\title{
INVESTIGATION OF GAS FOIL BEARINGS WITH AN ADAPTIVE AND NON-LINEAR STRUCTURE
}

\author{
Grzegorz ŻYWICA, 'Paweł BAGIŃSKI \\ *Department of Turbine Dynamics and Diagnostics, Institute of Fluid Flow Machinery, Polish Academy of Sciences, \\ ul. Fiszera 14, 80-231 Gdansk, Poland \\ gzywica@imp.gda.pl, pbaginski@imp.gda.pl
}

received 7 September 2018, revised 25 February 2019, accepted 28 February 2019

\begin{abstract}
The article discusses the results of simulation-based and experimental research carried out on gas foil bearings. Owing to the use of a set of flexible thin foils in such bearings, they exhibit certain beneficial features that cannot be found in other types of bearings. They have nonlinear operational characteristics and allow the dissipation of excess energy, thus reducing the vibration level. Moreover, gas foil bearings can self-adapt themselves to the current operating conditions by changing the shape of the lubrication gap. Therefore, they can be used to improve the dynamic performance of rotors, in particular, those operating at very high rotational speeds. This article explains the mechanisms for changes of stiffness and vibration damping in compliant components of a foil bearing. The results of the analysis of the bearing's subassemblies using advanced numerical models are presented. They are followed by conclusions that were drawn not only from these results but also from the results of the experimental research. It has been proven that the rotor supported on carefully designed foil bearings is capable of maintaining a low vibration level, even if it operates at a high rotational speed.
\end{abstract}

Key words: foil bearings, high-speed rotors, adaptive structure, non-linear stiffness

\section{INTRODUCTION}

Modern machines and devices have to meet increasingly higher requirements in terms of power efficiency and operational reliability. This also applies to devices used in distributed power generation, which additionally should be small in size and have a low impact on the surrounding environment (i.e., low noise and emissions). As far as cogeneration systems and trigeneration systems (in which heat energy is generated simultaneously with electricity and cold) are concerned, such requirements can easily be met by using high-speed fluid-flow machines such as microturbines (Kiciński, 2015, Kosowski et al., 2018, Włodarski, 2018). In order to enable microturbine rotors to operate at increasingly higher rotational speeds, novel bearing systems must be developed.

Foil bearings are one of the unconventional bearing systems (DellaCorte, 2012). An external lubricant supply system is not needed and such bearings are lubricated using air or a fluid situated in their immediate vicinity. Among all types of foil bearings that can be the components of a microturbine, gas foil bearings offer the greatest development potential for the future; they can be lubricated with the working medium from the thermodynamic cycle (which is the same medium that powers the microturbine). Owing to this, gas foil bearings can operate at high temperatures and high rotational speeds (even over 100,000 rpm). In comparison to rolling element bearings, which are de facto the most common type of bearings (Shen et al., 2014; Zhao et al., 2016), foil bearings have higher durability and improved vibration damping. Even though magnetic bearings can also be used in high-speed machinery (Ji et al., 2008), in particular, active magnetic bearings (Wu et al., 2018), the multi-component system of devices that are required to control the position of the rotor and a high price of such devices severely limit their usability. A somewhat new ap- proach in the field of bearing systems is the use of slide bearings with electrorheological and magnetorheological liquids as lubricants. The application of such liquids was aimed at changing to some extent the properties of the bearings (Peng and Zhu, 2005, Urreta et al., 2010). The electromagnetic field could be used to support the bearings' operation, improving their load capacity and dynamic characteristics. Work on such bearings is, however, at an initial stage, and their use at high temperatures is rather impossible. When discussing innovative bearing systems, shape memory alloys are worth mentioning. As demonstrated by the research already carried out, these types of alloys can be used to change the properties of supports in rotor-bearing systems (Enemark et al., 2015), which allows us to actively control the characteristics of the rotating system during its operation (in a certain range).

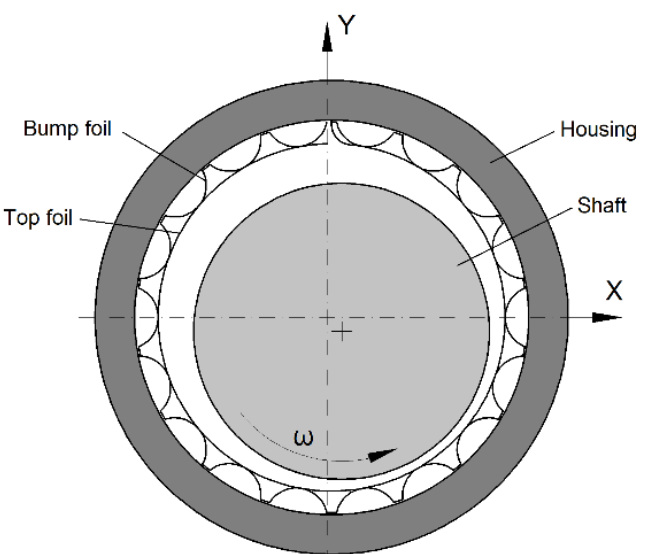

Fig. 1. The exemplary geometry of the first-generation foil bearing

All in all, foil bearings have the potential of wider utility in highspeed fluid-flow machines in the years to come. Although they 
have a fairly simple construction (Fig. 1), their operation is associated with physical phenomena whose experimental research requires advanced measurement techniques and computer-aided simulations should be conducted using sophisticated numerical models (von Osmanski et al., 2017). To improve the vibrationdamping capability of such bearings, additional elements in the form of thin foils are placed between the journal and the sleeve. They are not only capable of dissipating energy (Żywica et al., 2016a) but also enable changes in the shape of the lubrication gap during the bearing's operation, thus adapting it to the current operating conditions (Żywica et al., 2016b). The replacement of the foils makes it possible to change the stiffness of the bearing. Foils can have various thickness and the geometry of the bump foil can be modified. In this way, it is possible to alter the dynamic characteristics of the bearings and of the entire rotor-bearings system (Kiciński and Żywica, 2012). One can distinguish several generations of foil bearings (all of which have significantly different capacities), depending on the construction of the set of foils and the materials used (DellaCorte et al., 2008).

\section{SELF-ADAPTIVE PROPERTIES OF FOIL BEARINGS}

Thin metal foils used for the construction of foil bearings are characterized by high compliance. They change their shape depending on the current load and temperature. Because the support made of thin foils has very low inertia, it immediately reacts to dynamic excitations. The high compliance of the supporting elements makes it possible to change the properties of the foil bearings during their operation. At a certain speed (called lift-off speed) in a properly designed bearing, a thin gaseous layer forms itself between the mating elements, namely, between the journal and the top foil (Tkacz et al., 2017). Under these conditions, the bearing works wear-free. The assembly of top and bump foils should be designed in such a way that the fluid friction occurs in the widest possible ranges of speed and load. At the moment of increased static load, along with the movement of the journal towards the sleeve, the geometry of the assembly of foils should change in such a way that they become more rigid. Reacting to fast-changing dynamic loads, the top foil separated from the journal by a gas layer should move with it, and the bump foil should dissipate part of the energy of the rotating system and stabilise it. This principle of operation can be obtained thanks to the non-linear properties of the structural supporting layer. It can also be said that foil bearings have this unique capability of selfadapting themselves to demanding operating conditions (e.g., when they are subjected to external dynamic forces and/or large fluctuations of temperature). None of the classical slide bearings can withstand such operating conditions.

From the mechanical point of view, a foil bearing can be treated as the system shown in Fig. 2. This scheme includes all key subassemblies of the bearing that affect its static and dynamic properties. In general, it can be said that foil bearings resemble adaptive-passive systems for vibration reduction, which are used in various types of dynamic systems. Displacements and vibrations of the journal depend not only on characteristics of the lubrication film (which is speed-dependent) but also on the characteristics of the compliant assembly of foils, which changes as the load changes. In order to prevent high-amplitude vibrations, the assembly of foils that displays a progressive characteristic is usually used. A bearing that has such a characteristic is discussed in the following part of this article.

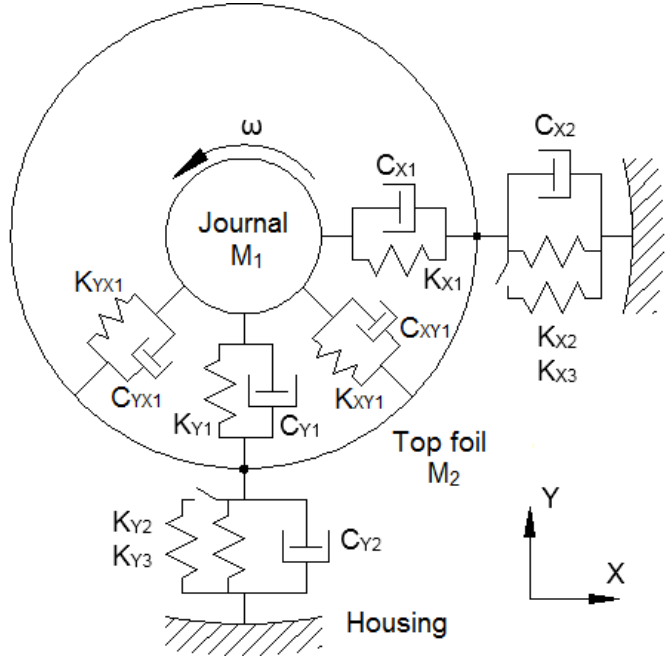

Fig. 2. Scheme of a foil bearing with the progressive stiffness ( $\mathrm{K}$ - stiffness, $\mathrm{C}$ - damping, $\mathrm{M}$ - mass)

The use of properly formed foils, made of carefully selected materials, enables long-lasting and wear-free operation of bearings (Howard, 1999; Żywica et al., 2016a). Because foil bearings do not require external lubrication and are able to ensure stable rotor operation at high rotational speeds, they have made a major contribution to the downsizing of turbomachinery while maintaining or sometimes even exceeding the original power level. Their drawbacks are the quite high starting torque and the lack of the lubrication film at low speeds (the reason for accelerated wear). Therefore, scientists and companies continue their efforts to improve the construction of foil bearings, which could soon allow us for the better use of their application potential. The development of foil bearings took a two-track approach: experimental research and numerical calculations. Much attention is also paid to tribology-related problems (Fanning and Blanchet, 2008; Gupta et al., 2009). As a matter of fact, a foil bearing is a very difficult system for theoretical description due to many mechanical processes that can not only coexist simultaneously but can also affect each other. Simplified models of such a bearing can be used only at the initial stage of the design engineering process. In many scientific centres, methods for modelling and analysing foil bearings are constantly developed (Aksoy et al., 2015), which are then verified using the results of experimental research (Żywica, 2013; Feng et al., 2015).

The following parts of the article present the selected results of the experimental research and computer-aided simulations, which all bear witness to the exceptional properties of foil bearings. The conducted experimental research has shown that the characteristics of a foil bearing can improve during its operation. A numerical analysis of a fragment of a foil bearing allowed to better understand the processes that occur during the build-up of the external load.

\section{EXPERIMENTAL INVESTIGATION}

\subsection{Experimental setup}

The experimental research was carried out on a test rig, which had been specially designed for testing foil bearings subjected to elevated temperature (Fig. 3). A high-speed electrospindle (which 
enables a smooth speed adjustment of up to $24,000 \mathrm{rpm}$ ) served to drive the rotor supported on two foil bearings. The bearing supports consist of two parts, which allows for easy replacement of bearing sleeves. All the elements of the test rig were attached to a steel plate. The plate was equipped with vibration isolation footers that isolated this plate from the frame bearer it is sitting on. The steel plate, rotor and bearing supports had a total mass of approx. $130 \mathrm{~kg}$. The measurement system enabled to measure the following parameters: rotational speed, relative vibrations of the rotor, absolute vibrations of bearing supports and temperature distributions in bearings.

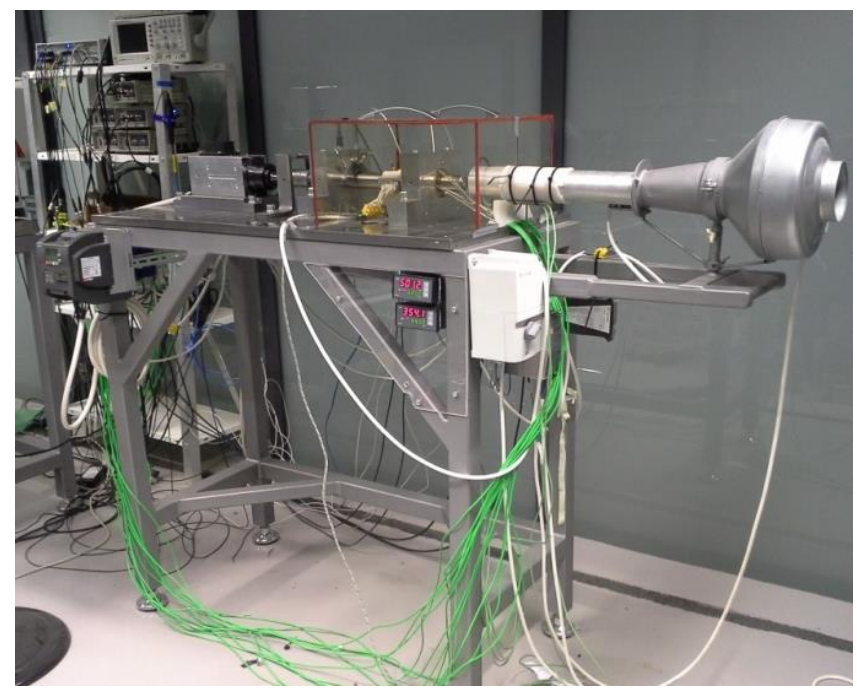

Fig. 3. The test rig for testing the rotor with foil bearings at elevated temperature

The research was conducted for the classical foil bearing, whose bump foils were made of several segments. Three bump foils were placed along the circumference of the bearing sleeve, and each of them consisted of 4 segments, obtained by a transverse cut of the foil. The geometry of the tested foil bearing was described in detail in a previous publication (Żywica et al., 2016a). The final shape of a bump foil was achieved by a two-step process. During the first stage, the bumps formed on a flat foil (Fig. 7). Next, the final curvature of a bump foil was obtained, having a radius almost equal to a radius of the hole in the bearing sleeve (Fig. 6). The nominal diameter of the tested foil bearing was 34 $\mathrm{mm}$ (a diameter of the journal). In order to assemble a bearing system, a journal must be pushed into a pre-assembled bearing, and such an arrangement has no radial clearance (assembly preload). After a gradual wearing-in of a bearing, when the mating foils fit smoothly, some radial clearance is obtained. The magnitude of the radial clearance depends on many factors, such as: ambient temperature, the way in which the wearing-in process proceeds, static and dynamic load, thickness of the top foil's coating and so on.

\subsection{Experimental results}

In the course of the research, it turned out that the dynamic and thermal characteristics of the foil bearings changed during their operation. It was the most noticeable during the run-up and run-down of the rotor. Very interesting results were obtained for the bearing with a new top foil in which the antifriction coating was wearing-in during the first seconds of the operation. A plot that presents how the temperature of the top foil of this bearing (measured in its bottom part, at the central cross-section) was changing is shown in Fig. 4. The measurement was made using a thermocouple, whose measuring junction was in contact with the top foil. The rotational speed of the rotor was increased gradually and a speed of $15,000 \mathrm{rpm}$ was reached after 50 seconds. This speed was maintained until the 230th second of the measurement, and then it was reduced to $12,000 \mathrm{rpm}$. At the beginning of the measurement, the temperature of the top foil increased rapidly up to $65^{\circ} \mathrm{C}$ at the maximum speed. Subsequently, the temperature of the foil dropped equally quickly, and after the 150th second, it was lower than $35^{\circ} \mathrm{C}$.

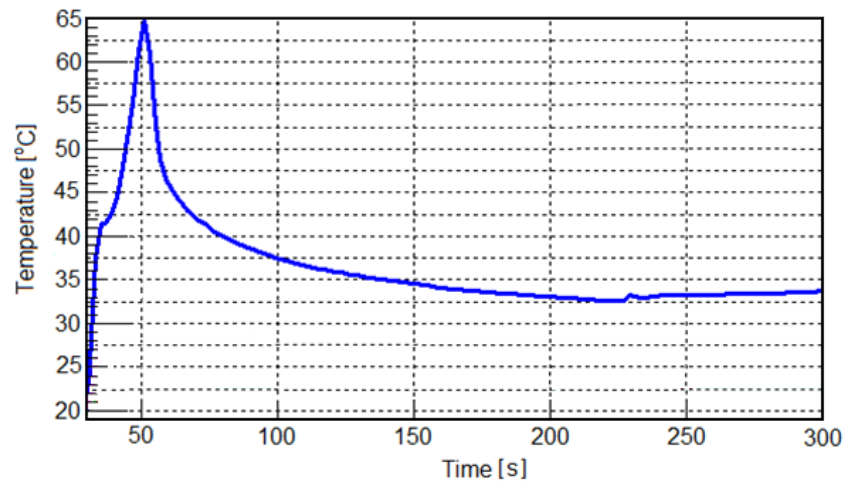

Fig. 4. Temperature of the top foil measured during wearing-in process vs. time of operation

The temperature distribution resulted from the bearing load and rotational speed. The highest load - gravitational force, was acting at the bottom of the bearing. It was noted that the increase of temperature was accompanied with higher friction torque, which impeded the start-up of the rotor. Subsequently, after wearing-in of the fop foil and journal coating, friction decreased significantly and the speed control of the electrospindle using a frequency converter was much easier.

During the discussed research, measurements of absolute vibrations of bearing pedestals and relative vibrations of the rotor were also made. The measurement results of the relative vibrations of the bearing journals showed that for the speeds lower than the lift-off speed (in the area of mixed friction), vibration amplitudes of the journals were high and reached a value of 0.4 $\mathrm{mm}$ (Fig. 5). After the rotor achieved a speed of $20,000 \mathrm{rpm}$, the vibration amplitude of both bearings declined significantly and remained at a very low level (about $0.04 \mathrm{~mm}$ ). Such a low vibration level indicated very good dynamic properties of the rotating system equipped with foil bearings.

On the basis of the obtained outcomes of the research, it can also be noted that when the rotational speed of the rotor increased, the foil bearing constantly adapted itself to the everchanging operating conditions. At low speeds, when there were no gaseous films in the bearings yet, the vibration level was quite small, which results from the very good vibration-damping capability of the thin foils. Then, when the rotational speed was increased, an increase in vibration level of the rotor could be observed until stable lubricating films formed themselves in the bearings. The largest vibration amplitudes occurred at the speeds from the range of $8,000 \mathrm{rpm}$ to $10,000 \mathrm{rpm}$ when the lubricating film was not stable yet and there was a physical contact between the journal and the top foil (Fig. 5). Moreover, at these speeds, the 
rotating journal kept on rubbing itself against the antifriction coating of the top foil. The operation at these speeds is the most unfavourable for the tested foil bearing as fast wear can occur. Therefore, it is important to rapidly increase the speed of the rotor to not let it work at dangerous speeds for too long. At higher speeds, gaseous lubricating film stabilises itself in the bearing and the flexible foils adapt their shape to new operating conditions. In these conditions, the gaseous supporting layer usually has a thickness of a few to a dozen or so micrometres, which means that it is very rigid and has poor vibration-damping capability. The set of appropriately formed foils has then the role of a damping element; it enables the rotor to rotate at extremely high speeds and the vibration level is very low.

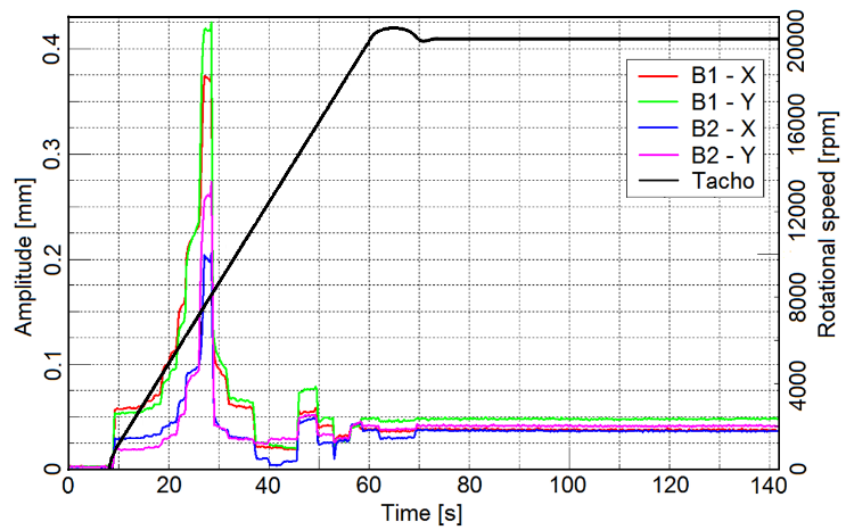

Fig. 5. The relative vibrations of the bearing journals during the run-up of the rotor up to a speed of $20,000 \mathrm{rpm}$ vs. time (B1 - bearing No. 1 , $\mathrm{B} 2$ - bearing No. 2, $\mathrm{X}$ and $\mathrm{Y}$ - horizontal and vertical direction)

\section{NUMERICAL ANALYSIS OF FOIL BEARINGS}

Due to the small size of the flexible elements of the foil bearing and their very small displacements during operation (at the level of micrometres), their measurement on the test rig is very difficult in practice. That is why an advanced numerical model, which had been developed using the finite element method (FEM), was used to thoroughly analyse the deformations and displacements of the top and bump foils.

\subsection{Non-linear model of the foil bearing structure}

An analysis of foil bearings must take into account the nonlinear properties of the structural supporting layer, which arise from its geometry and the support conditions. This section of the article discusses the model of the foil bearing structure implemented in the Abaqus CAE interface and developed using the finite element method. A three-dimensional numerical model has been developed in order to represent the geometry of the actual system as faithfully as possible. In this model, the contact phenomena between all mating surfaces (including friction) were also considered. In the first-generation foil bearings, the structural supporting layer consists of elastic damping elements that are evenly spaced along the perimeter; the top foil rests on these elements. Therefore, only a fragment of the assembly of foils was implemented in the numerical model for the purposes of analyses, the purpose of which was to provide only a general explanation of the mechanical processes occurring during loading the system.
The rationale behind doing so is the fact that in a majority of modern foil bearings, the above-mentioned layer consists of several sets of short bump foils (evenly spaced along the circumference) on which the top foil rests. So the properties of the whole set of foils are affected by the characteristics of its component parts, namely the characteristics of individual fragments of the bump foil. Fig. 6 demonstrates the analysed zoomed-in fragment of the structural supporting layer and its location on the sleeve.
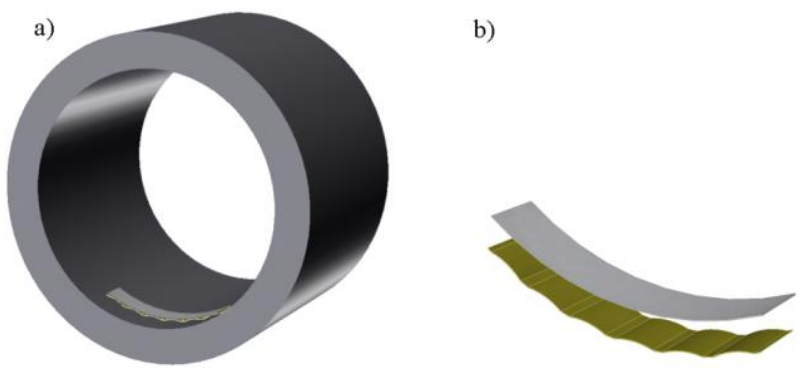

Fig. 6. The analysed fragment of the foil bearing (a - location in the bush, $b$ - zoomed-in fragment of the top and bump foils

Simulations were conducted using the model in which the sleeve curvature was not taken into account. Such an approach is quite common in the literature (Le Lez et al., 2007). Exact dimensions of the top and bump foils, incorporated into the model that served for the analysis of the assembly of these foils, are shown in Fig. 7. It was assumed that both foils were made of steel with the following properties: $\rho=7,800 \mathrm{~kg} / \mathrm{m}^{3}, E=2.1 \cdot 10^{11} \mathrm{~Pa}$ and $\mathrm{v}=$ 0.3 .
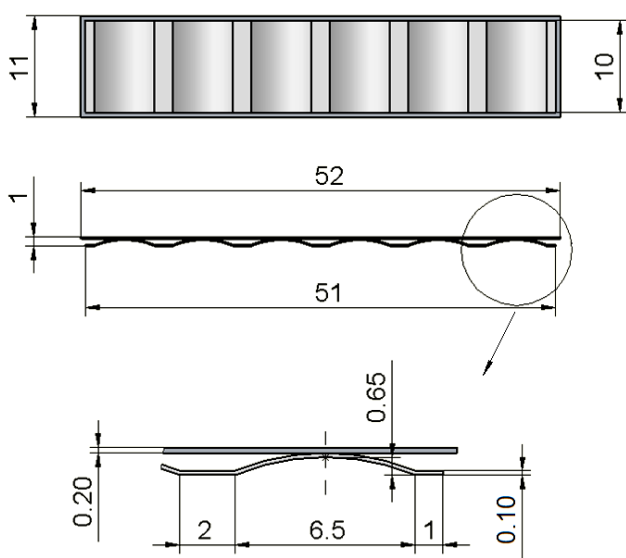

Fig. 7. Dimensions of the analysed fragment of the foil bearing

In order to carry out a deformation analysis of the assembly of foils, the following boundary conditions were adopted: (1) constraints corresponding to all the outer edge nodes of the top foil are symmetrical (such boundary conditions are used when there is a need to analyse only a fragment of a system in which displacements in the direction perpendicular to the parting plane are not important); (2) the sleeve surface on which the bump foil rests is treated as infinitely rigid (account has to be taken of the fact that very considerable difference exists between the stiffness of thin steel foils and of the sleeve made of solid material); (3) displacements of the one end of the bump foil were limited by fixing all 
degrees of freedom, thus creating a rigid connection with the sleeve; (4) surface-to-surface contact elements were used to model contact between the upper surface of the bump foil and the lower surface of the top foil as well as between the lower surface of the top foil and the surface of the sleeve; (5) coefficient of friction was set to 0.1 .

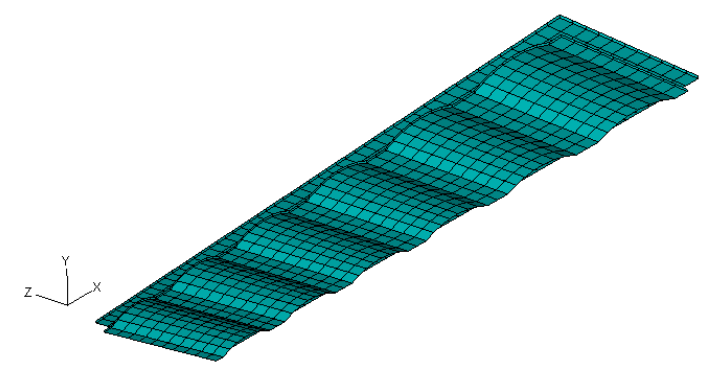

Fig. 8. FEM model of the assembly of foils

Figure 8 presents a discrete model of the assembly of foils, obtained after the optimisation of the FEM mesh. The accuracy and time of calculations were the optimisation criteria used. Three-dimensional hexahedral finite elements of the type C3D8R were employed. These are eight-node brick elements with reduced integration. Such elements are recommended for the analyses in which contact phenomena occur. The FEM model being discussed herein was also subjected to an experimental verification, the outcomes of which confirmed its high usefulness in predicting the properties of the structural supporting layer (Żywica, 2013). Some other time, a model of the structural part of a foil bearing, developed in a similar manner, was used for the simulation analysis aimed, among other things, to investigate the impact of various parameters on the properties of the structural supporting layer of a foil bearing, taking into account such parameters as the foil thickness, the number of bumps and their geometry, properties of the construction material and the coefficient of friction. Similar analyses are often done at the development stage of new foil bearings and allow for their optimisation, thus narrowing the scope of experimental tests to be carried out.

\subsection{Predicted characteristics of foil bearings}

In this section of the article, we would like to take a closer look at the foil bearing's structure and its geometric nonlinearity that has a very significant impact on both static and dynamic properties of each rotating system equipped with such a bearing. It turns out that the stiffness of the tested bearing can change greatly during its operation and is strongly dependent on the level of loading (Fig. 9). In the case study in question, the assembly of foils was subjected to the pressure that acted on the top foil. The same process of loading the foils occurs in a real foil bearing after a gaseous lubricating film formed itself. During the analysis, the pressure was higher than in a real foil bearing (it usually does not exceed $0.2 \mathrm{MPa}$ ), and this approach allowed to determine the characteristics in a broader range. Such a high pressure may only occur for a short period of time, for example, as a result of dynamic loads. The curve that shows the displacement of the top foil is almost linear for low pressure, but after exceeding a value of 0.35 $\mathrm{MPa}$, its character changes. A similar change can be observed when the load was increased to $0.65 \mathrm{MPa}$, which means that the stiffness of the assembly of foils had increased even more.

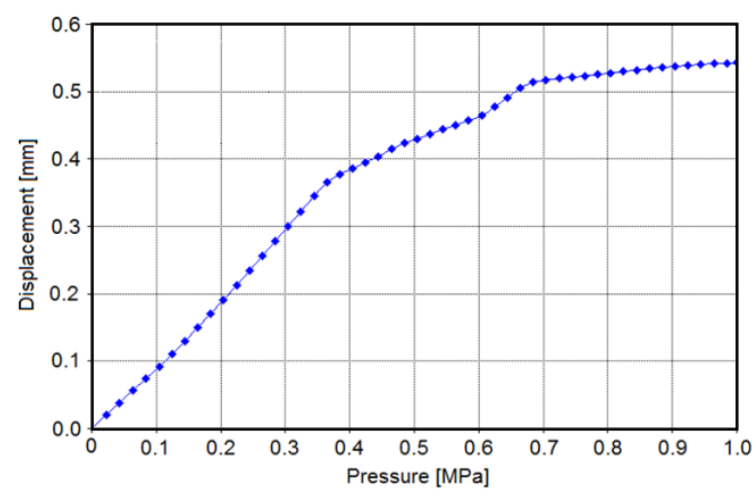

Fig. 9. Displacement of the top foil vs. load

a)

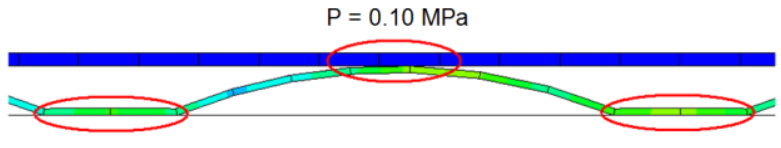

b)

$\mathrm{P}=0.35 \mathrm{MPa}$

c)

$\mathrm{P}=0.65 \mathrm{MPa}$

d)

$\mathrm{P}=1.00 \mathrm{MPa}$

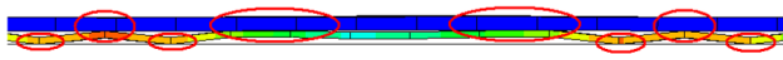

Fig. 10. The occurrence of additional contact points between the top and bump foils, according to the load (a-d)

A thorough analysis of deformations of the assembly of foils (using the developed FEM model) shed some light on this anomaly. It turned out that these deformations depend upon the level of load and are related directly to the way in which the top and bump foil interact with each other (Fig. 10). As the load increases, a higher number of support points between the mating foils appear and the higher the load, the more support points occur (Fig. 10b and Fig. 10c). At the highest load, the bump foil became nearly flat (Fig. 10d), which means that the system has a very high stiffness. The same can be observed at a lower load when thinner foils are used. This progressive nature of the structural supporting layer is beneficial because displacements of the bearing journal decrease as the load increases. This fact also has a good effect on the accuracy of the shaft alignment. The analysed process of loading is irreversible, as part of the energy of the system is dissipated as a result of friction. The bump foil is fixed on one end only, and thus, the pressure exerted by the top foil causes the bump foil to move along the surface of the sleeve. This has a beneficial effect on the dynamics of the rotor, because it reduces the vibration level. It can even be said that the shape of the bump foil allows the rigidity of the support to adjust itself to the acting load. In this way, one can explain why the bearing was able to adjust itself to the current operating conditions of the rotor, what was observed during the experimental research. Due to the high compliance of the structural supporting layer at lower loads, there was no direct contact between the journal and the top foil because the stiffness of the thin gaseous lubricating film was higher than the stiffness of the structure. A high rotational speed must, however, be considered as one of the conditions for the appearance of a stable lubricating film. 


\section{CONCLUSIONS}

The article discusses selected issues related to distinctive features of gas foil bearings. Particular attention was paid to the selfadaptation capability of such bearings to the current operating conditions and their non-linear properties. Selected results of the experimental and computational research were presented and discussed. Results of the experimental research have shown that both dynamic and thermal characteristics of gas foil bearings can change significantly during the operation of a turbomachine. Simulations, on the other hand, allowed to improve knowledge and understanding of mechanical phenomena in which structural components of bearings play a key role. The performed analyses are also proof that the stiffness of a foil bearing can be modified to a very large extent, which greatly facilitates adjusting its characteristics to a particular rotating system. A foil bearing with an active regulation of its stiffness during operation is one of the new areas of research. It can be done using smart materials and electronic control systems. Work on these issues is already ongoing and will be continued by the authors of this article (Lubieniecki et al., 2016).

Gas foil bearings have some distinctive properties that are unheard of in other bearing types. The structural supporting layer of such a bearing has a progressive stiffness, which means that its deformations decrease progressively as the load increases. The main advantage of a foil bearing is the capability of adjusting itself to the load conditions. This capability has been verified experimentally, namely, it was observed that the vibration level of bearing journals was very low at high rotational speeds. Even though there was a sharp increase in the bearing temperature and in the vibration amplitude during the run-up of the rotor (observed within a very narrow speed range), the system exhibited very good dynamic properties after the speed was further increased. That is why foil bearings are increasingly being used in newly designed fluid-flow machinery equipped with lightly loaded rotors that rotate at high speeds.

\section{REFERENCES}

1. Aksoy S., Aksit M.F. (2015), A fully coupled 3D thermoelastohydrodynamics model for a bump-type compliant foil journal bearing, Tribology International, 82, 110-122.

2. DellaCorte C. (2012), Oil-Free shaft support system rotordynamics: Past, present and future challenges and opportunities, Mechanical Systems and Signal Processing, 29, 67-76.

3. DellaCorte C., Radil K.C., Bruckner R.J., Howard A. (2008), Design, Fabrication, and Performance of Open Source Generation I and II Compliant Hydrodynamic Gas Foil Bearings, Tribology Transactions, 51(3), 254-264.

4. Enemark S., Savi M.A., Santos I.F. (2015), Experimental analyses of dynamical systems involving shape memory alloys, Smart Structures and Systems, 15(6), 1521-1542.

5. Fanning C.E., Blanchet T.A. (2008), High-temperature evaluation of solid lubricant coatings in a foil thrust bearing, Wear, 265, 10761086.

6. Feng K., Hu J., Liu W., Zhao X., Li W. (2015), Structural characterization of a novel gas foil bearing with nested compression springs: analytical modeling and experimental measurement, ASME Journal of Engineering for Gas Turbines and Power, 138(1), 012504-11.

7. Gupta S., Filimonov D., Zaitsev V., Palanisamy T., El-Raghy T., Barsoum M.W. (2009), Study of tribofilms formed during dry sliding of Ta2AlC/Ag or Cr2AlC/Ag composites against Ni-based superalloys and Al2O3, Wear, 267, 1490-1500.

8. Howard S.A. (1999), Rotordynamics and design methods of an oilfree turbocharger, Tribology Transactions, 42(1), 174-179

9. Ji J.C., Hansen C.H., Zander A.C. (2008), Nonlinear dynamics of magnetic bearing systems, Journal of Intelligent Material Systems and Structures, 19(12), 1471-1491.

10. Kiciński J. (2015), The dynamics of microturbines lubricated using unconventional agents, Bulletin of the Polish Academy of Sciences: Technical Sciences, 63(2), 369-377.

11. Kiciński J., Żywica G. (2012), The numerical analysis of the steam microturbine rotor supported on foil bearings, Advances in Vibration Engineering, 11(2), 113-119.

12. Kosowski K., Piwowarski M., Stępień R., Włodarski W. (2018), Design and investigations of the ethanol microturbine, Archives of Thermodynamics, 39(2), 41-54.

13. Le Lez S., Arghir M., Frene J. (2007), Static and dynamic characterization of a bump-type foil bearing structure, Journal of Tribology, 129, 75-83.

14. Lubieniecki M., Roemer J., Martowicz A., Bagiński P., Żywica G., Uhl T. (2016), An experimental evaluation of the control methodology for distributed actuators integrated within a foil bearing, ICAST2016, $27^{\text {th }}$ International Conference on Adaptive Structures and Technologies, New York, USA.

15. Peng J., Zhu K.-Q. (2005), Hydrodynamic characteristics of ER journal bearings with external electric field imposed on the contractive part, Journal of Intelligent Material Systems and Structures, 16(6), 493-499.

16. Shen C., Wang D., Liu Y., Kong F., Tse P.W. (2014), Recognition of rolling bearing fault patterns and sizes based on two-layer support vector regression machines, Smart Structures and Systems, 13(3), 453-471.

17. Tkacz E., Kozanecki Z., Kozanecka D., Lagodziński J. (2017), A self-acting gas journal bearing with a flexibly supported foil Numerical model of bearing dynamics, International Journal of Structural Stability and Dynamics, 17(5), 1740012

18. Urreta H., Leicht Z., Sanchez A., Agirre A., Kuzhir P., Magnac G. (2010), Hydrodynamic bearing lubricated with magnetic fluids, Journal of Intelligent Material Systems and Structures, 21(15), 14911499

19. Von Osmanski S., Larsen J.S., Santos I.F. (2017), A fully coupled air foil bearing model considering friction - Theory \& experiment, Journal of Sound and Vibration, 400, 660-676.

20. Włodarski W. (2018), Experimental investigations and simulations of the microturbine unit with permanent magnet generator, Energy, 158, 59-71.

21. Wu R.Q., Zhang W., Yao M.H. (2018), Nonlinear dynamics near resonances of a rotor-active magnetic bearings system with 16-pole legs and time varying stiffness, Mechanical Systems and Signal Processing, 100, 113-134.

22. Zhao Y., Zhang B., An G., Liu Z., Cai L. (2016), A hybrid method for dynamic stiffness identification of bearing joint of high speed spindles, Structural Engineering and Mechanics, 57(1), 141-159.

23. Żywica G. (2013), The dynamic performance analysis of the foil bearing structure, Acta Mechanica et Automatica, 7(1), 58-62.

24. Żywica G., Bagiński P., Banaszek S. (2016a), Experimental studies on foil bearing with a sliding coating made of synthetic material, Journal of Tribology, 138(1), 011301.

25. Żywica G., Kiciński J., Bagiński P. (2016b), The static and dynamic numerical analysis of the foil bearing structure, Journal of Vibration Engineering \& Technologies, 4(3), 213-220.

The research was financed by the National Science Centre in Poland, under the research project No. 2016/21/D/ST8/01711 entitled 'Examination and modelling of anti-vibration processes occurring in high-speed bearings with variable geometry'. 